\title{
Emerging role of transient receptor potential (TRP) channels in cancer progression
}

\author{
Dongki Yang ${ }^{1}$ \& Jaehong Kim $^{2}$ ** \\ Departments of ${ }^{1}$ Physiology and ${ }^{2}$ Biochemistry, College of Medicine, Gachon University, Incheon 21999, Korea
}

\begin{abstract}
Transient receptor potential (TRP) channels comprise a diverse family of ion channels, the majority of which are calcium permeable and show sophisticated regulatory patterns in response to various environmental cues. Early studies led to the recognition of TRP channels as environmental and chemical sensors. Later studies revealed that TRP channels mediated the regulation of intracellular calcium. Mutations in TRP channel genes result in abnormal regulation of TRP channel function or expression, and interfere with normal spatial and temporal patterns of intracellular local $\mathrm{Ca}^{2+}$ distribution. The resulting dysregulation of multiple downstream effectors, depending on $\mathrm{Ca}^{2+}$ homeostasis, is associated with hallmarks of cancer pathophysiology, including enhanced proliferation, survival and invasion of cancer cells. These findings indicate that TRP channels affect multiple events that control cellular fate and play a key role in cancer progression. This review discusses the accumulating evidence supporting the role of TRP channels in tumorigenesis, with emphasis on prostate cancer. [BMB Reports 2020; 53(3): 125-132]
\end{abstract}

\section{INTRODUCTION}

The onset and progression of cancer is characterized by cell cycle dysregulation, leading to enhanced cell growth, concomitant with suppression of mechanisms responsible for cell death (1-4). Notably, dysregulated homeostasis of intracellular $\mathrm{Ca}^{2+}$ is involved in cancer. Altered $\mathrm{Ca}^{2+}$ signaling events induced by ion fluxes across various membrane channels and transporters mediate every step of cancer metastasis (5). Intracellular free calcium ions $\left(\left[\mathrm{Ca}^{2+}\right]_{\mathrm{i}}\right)$ are the most abundant second messengers in human body playing a diverse role in cellular physiology, including cell motility, cell cycle control, gene expression, autophagy and apoptosis (6). Multiple mech-

*Corresponding author. Tel: +82-32-899-6441; Fax: +82-32-899-6588; E-mail: geretics@gachon.ac.kr

https://doi.org/10.5483/BMBRep.2020.53.3.016

Received 14 January 2020

Keywords: Calcium signaling, Cancer, Mechanotransduction, Metastasis, Prostate cancer, TRP channel anisms regulating cell growth or apoptosis are strongly dependent on $\left[\mathrm{Ca}^{2+}\right]_{i}$ homeostasis, emphasizing the role of calciumpermeable ion channels. Excitable cells contain highly selective and voltage-sensitive $\mathrm{Ca}^{2+}$ channels, which induce sharp and sustained elevation in $\left[\mathrm{Ca}^{2+}\right]_{i}$ required for exocytosis at nerve termini, and for rapid contraction of muscle fibers in heart and skeletal muscles. Non-excitable cells such as fibroblasts use a different mechanism. For example, ligand binding to several membrane receptors triggers a series of events, leading to the activation of phospholipase C (PLC) and synthesis of inositol-1,4,5-trisphosphate $\left(\operatorname{Ins}(1,4,5) \mathrm{P}_{3}\right) . \operatorname{Ins}(1,4,5) \mathrm{P}_{3}$ opens the Ins $(1,4,5) P_{3}$ receptor $\left(I P_{3} R\right)$, which is an intracellular ion channel and expressed mostly in the endoplasmic reticulum, resulting in the release of $\mathrm{Ca}^{2+}$ from the endoplasmic reticulum $(7,8) . \mathrm{Ca}^{2+}$ signals in the form of spikes, oscillations or waves are spatially and temporally tightly regulated (9) to avoid prolonged intracellular elevation of $\mathrm{Ca}^{2+}$ that is toxic and lethal for cells (10). The duration, frequency, and amplitude of $\left[\mathrm{Ca}^{2+}\right]_{\mathrm{i}}$ oscillatory signals determine the selective $\mathrm{Ca}^{2+}-$ specific activation of transcription factors for cellular proliferation and migration $(11,12)$. Downstream effectors, in-

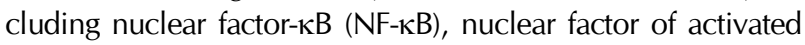
T-cells (NFAT), calmodulin (CaM), calmodulin-dependent protein kinase II (CaMKII) and calpain, decode the selective oscillatory $\left[\mathrm{Ca}^{2+}\right]_{\mathrm{i}}$ signals. Mechanistically, the differences in their on-/off-rates for $\mathrm{Ca}^{2+}$ enable subsequent activation of different cellular events (13-15). For example, calcineurin, a calciumdependent serine-threonine phosphatase, and calpains, calciumdependent cysteine proteases are crucial calcium-dependent factors that regulate the cell cycle. These findings emphasize the importance of subtle and local changes in $\left[\mathrm{Ca}^{2+}\right]_{\mathrm{i}}$ in the regulation of cell fate, prompting the investigation of alternate pathways regulating local delivery of $\mathrm{Ca}^{2+}$.

Notably, a re-evaluation of accepted paradigms of intracellular regulation of $\mathrm{Ca}^{2+}$ appears to be imminent. Interestingly, many recent studies investigated new functions of specific members of the transient receptor potential (TRP) superfamily (16-18) that will be discussed with an emphasis on cancer biology. While the traditional role of TRP channels is confined to 'pain' perception via nociceptive neurons (19), drug discovery efforts targeting TRP channels have expanded into new disease areas such as chronic cough, asthma, chronic itch, obesity, overactive bladder, anxiety, stroke and cancer. In the

ISSN: 1976-670X (electronic edition)

Copyright (c) 2020 by the The Korean Society for Biochemistry and Molecular Biology

(ㄷ) This is an open-access article distributed under the terms of the Creative Commons Attribution Non-Commercial License (http://creativecommons.org/licenses/by-nc/4.0) which permits unrestricted non-commercial use, distribution, and reproduction in any medium, provided the original work is properly cited. 
last decade, the role of TRP channels in enhancing cellular proliferation, abnormal differentiation, and impaired death, resulting in uncontrolled expansion and invasion of cancer, has been increasingly reported (20-22). Metastasis, a major hallmark of cancer, is characterized by the spread and invasion of cancer cells from the primary location to distant organs $(23,24)$. When metastasis happens, cancer as a disease that can be potentially curable by surgical excision is converted into one that requires chemotherapy and may even become lethal. Studies investigating several cancer types have shown that tumor progression from early to late stages is often characterized by the altered expression of TRP channels. Indeed, TRPs have been implicated in cancers of prostate, breast, kidney, and bladder as well as in glioma and melanoma (20, 21). To date, TRP channels have been shown to play a role in various late stages of tumor progression rather than carcinogenesis.

\section{TRP CHANNELS}

The TRP superfamily is mostly conserved from nematodes to humans, and comprises a diverse group of polymodal ion channels. By altering membrane potential or $\left[\mathrm{Ca}^{2+}\right]_{i}$ concentration, the TRP channels act as signal transducers. The era of TRP channels started in 1969 when blindness was classified as a phenotype even under constant bright light, based on a Drosophila study (25) and identification of the mutant trp gene revealed the first member of the TRP superfamily. The mammalian TRP channel superfamily is divided into six subfamilies: TRPC (Canonical), TRPML (Mucolipin), TRPM (Melastatin), TRPV (Vanilloid), TRPP (Polycystic), and TRPA (Ankyrin). As shown in Fig. 1, structural variance across the six subfamilies is compared. The first four subfamilies constitute group 1 and the last two represent group 2. Several TRP chan- nels are known targets of S-nitrosylation, which has been shown to activate multiple TRP channels, indicating their role as nitric oxide (NO) sensors (26). Many oncoproteins undergo S-nitrosylation. Nevertheless, there is no direct evidence indicating that S-nitrosylation of TRP channels is directly involved in carcinogenesis (27). All TRPC members are characterized by an $\mathrm{N}$-terminus ankyrin-like repeat domain (ARD), a TRP box after the sixth transmembrane segment, $\mathrm{S} 6$, and $\mathrm{a} \mathrm{Ca}^{2+}$-binding $\mathrm{EF}$ hand domain at the intracellular $\mathrm{C}$ terminus. Generally, the phospholipase $\mathrm{C}(\mathrm{PLC})$ signaling pathway activates all the TRPC channels. TRPC subunits assemble into homomeric channels, and many of the subunits also form heteromeric channels (28-31). TRPC1/TRPC5 (32), TRPC1/TRPC3 (33), TRPC1/TRPC4 (34), TRPC1/TRPC3/TRPC7 (35), TRPC3/TRPC4 (36), and TRPC4/TRPC5 $(37,38)$ are examples of heteromeric channels. Despite its function in other mammals, human TRPC2 is uniquely considered as a pseudogene.

TRPML1, 2, and 3 represent the TRPML subfamily, which primarily includes cytosolic proteins. Their subcellular localization appears to be determined by an ER retention-signaling domain in the intracellular $\mathrm{C}$ terminus. Co-assembly of TRPML subunits has also been reported $(39,40)$.

The mammalian TRPM subfamily includes TRPM1-8. TRPM channels are categorized into three subgroups: TRPM1/TRPM3, TRPM4/TRPM5 and TRPM6/TRPM7; TRPM2 and TRPM8 are separated from the rest of the subfamily. TRPM subunits contain a large TRPM homology region of around 700 amino acids in their very long $\mathrm{N}$ termini. Most TRPM subunits also contain a C-terminus TRP box and a coiled-coil domain (41). Among the TRP channels, TRPM4 and TRPM5 are unique in that they are monovalent cation-selective ion channels. Additionally, TRPM2, TRPM6, and TRPM7 contain a unique enzymatic domain in their $\mathrm{C}$ termini. TRPM6 and TRPM7 assemble to form heteromeric channels (42-45).
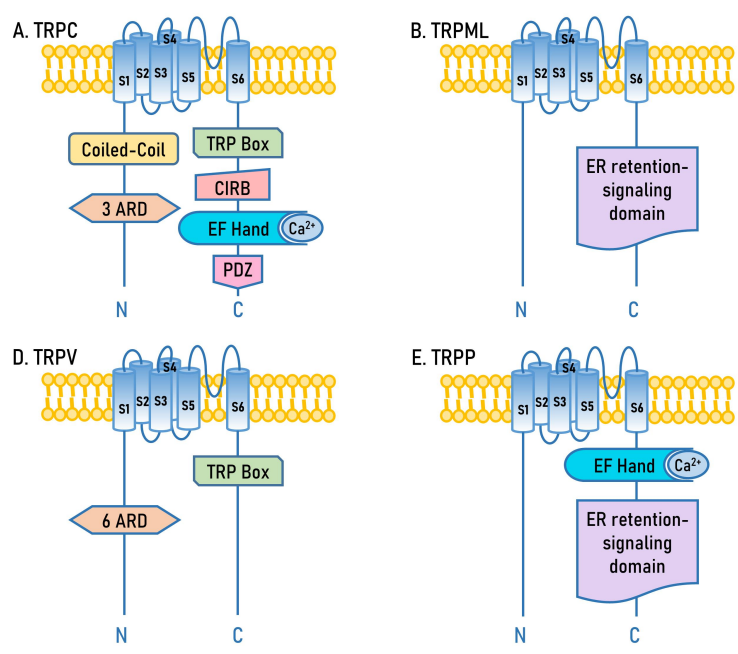

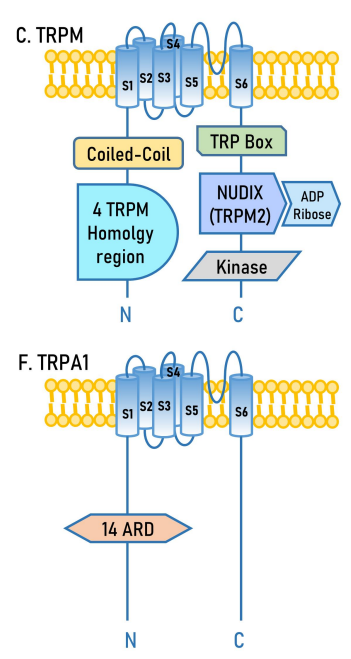

Fig. 1. A schematic diagram comparing the protein structures of TRP subfamilies. TRP proteins carry six transmembrane segments (S1 to S6). (A, E) TRPC and TRPP subfamilies contain EF hand domain that binds intracellular $\mathrm{Ca}^{2+}$. (A) CIRB is a calmodulin/IP3R-binding domain. (B, E) TRPML and TRPP contain ER retention signlaling domain. (C) NUDIX, named after nucleoside diphosphate-linked moiety- $X$, is a homologous region in the phosphohydrolase family that binds to ADP ribose. The NUDIX represents a unique activation mechanism, gating by ADP ribose, on TRPM2. Other activators, such as cyclic ADPR and $\mathrm{NAD}+$, as well as inhibitors also target the NUDIX. C-terminal serine/threonine kinase is similar in structure to protein kinase A. (D) TRPV contains ARD and TRP box, similar to TRPC. (F) TRPA1 contains more than 14 ARDs at its N-terminus. 


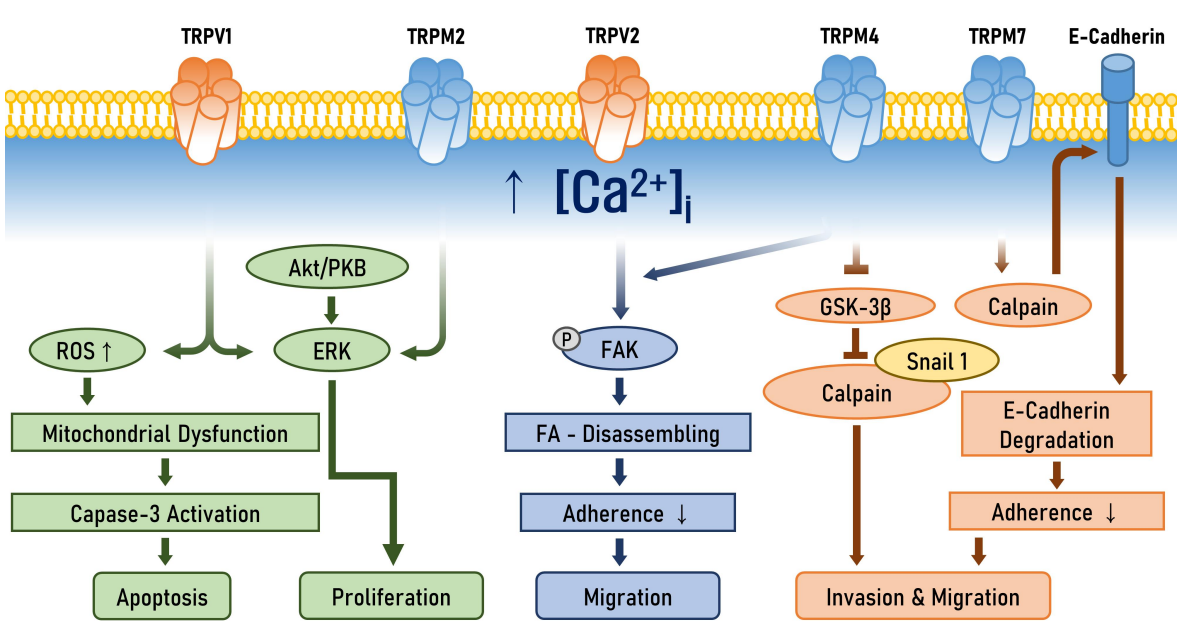

Fig. 2. A working model of the representative mechanisms of calcium signaling mediating the metastatic role of multiple TRP channels. FA: focal adhesion.
TRPV1-6 constitute the TRPV subfamily. TRPV channels are categorized into two groups: TRPV1-4 and TRPV5/TRPV6. The first group of TRPV1-4 form homomeric channels that are weakly $\mathrm{Ca}^{2+}$-selective and activated by heat. Each subunit of the TRPV1-4 group can also co-assemble to form heteromeric channels (46-49). TRPV5 and TRPV6 form both heteromeric and homomeric channels and are highly $\mathrm{Ca}^{2+}$ selective but not heat activatable. Similar to TRPCs, subunits of this subfamily also contain an ARD and a TRP box domain. Subunit assembly is promoted by the specific interacting domains in the $\mathrm{C}$ terminus (50-52).

The TRPP subfamily comprises TRPP2 (also known as PKD2), TRPP3 (or PKD2L1), and TRPP5 (or PKD2L2). TRPP subunits also carry an ER retention-signaling domain in their C-termini. TRPA 1 is the only member of the TRPA subfamily and is named after its ARD domain, carrying at least 14 large and unique repeats.

\section{TRP CHANNELS IN CANCER METASTASIS}

The mechanotransduction events during metastasis increasingly provide a new perspective for the understanding of mechanisms involved in cancer progression. The stiffness of tumor microenvironment in solid tumors enhances the activation of mechanotransduction signals in cancer cells to promote pro-metastatic architecture, including cancer cell invasion and metastasis, which are essential for the development of advanced disease (53-55).

Some members of the TRP channel superfamily are functionally related to cellular events and structures that are essential for mechanotransduction in cell migration, such as actin cytoskeleton and focal adhesions. Consequently, they are involved in mechanotransduction by significantly contributing to metastasis, presumably by strongly promoting cancer cell migration and invasion. In the context of metastasis, TRPM7, a
$\mathrm{Ca}^{2+}$-nonselective cation channel carrying $\alpha$-kinase domain (56), appears to be the best studied TRP channel so far. TRPM7 regulates several events in cell motility such as polarization (57), adhesion $(58,59)$ and migration (60). We summarize the representative signaling mechanisms underlying the function of specific TRP channels, in Fig. 2.

A study with a mouse xenograft model of human breast cancer also showed that TRPM7 is necessary for tumor metastasis and that high mRNA expression of TRPM7 is correlated with reduced metastasis-free and recurrence-free survival in patients with primary breast cancer (61). Myosin-II-based cell tensions and loss of cell matrix proteins regulating cell-cell adhesion, and polarized cell movement occurred via TRPM7dependent mechanisms (61). TRPM7 is activated by tension at the leading edge of migrating human embryonic lung fibroblasts, promoting $\mathrm{Ca}^{2+}$ entry to activate the IP3R2, resulting in local $\mathrm{Ca}^{2+}$ fluctuations necessary for cell migration (62). Overexpression of TRPM7 has also been linked to loss of cell adhesion via activation of calpain II (63). Accordingly, TRPM7 silencing via knockdown of MDA-MB-231 or MDA-MB-435 breast cancer cells increases contractility and the number of focal adhesions, which is strongly correlated with reduced migratory and invasive potencies (61). Notably, it has been suggested that the role of TRPM7 in calcium-independent regulation of migration is at least partly mediated via $\alpha$-kinase domain, during the phosphorylation of myosin-IIA heavy chain (64-66).

In nasopharyngeal cancer, the increased expression of TRPM7 is associated with poor prognosis and metastasis (67). Similar to breast cancer cells, silencing of TRPM7 decreases the migration and invasion of metastatic cancer cells, and also the overexpression of TRPM7 increases both phenomena in nonmetastatic cancer cells (67). The contribution of TRPM7 to migration of human nasopharyngeal cancer cells is attributed to ryanodine receptor (RyR) activation, which consequently increases 
$\left[\mathrm{Ca}^{2+}\right]_{\mathrm{i}}$ levels and cellular migration (68). Thus, TRPM7 directly affects the migration of diverse cancer cell types via mechanotransduction mediated by $\left[\mathrm{Ca}^{2+}\right]_{\mathrm{i}}$.

TRPM7 is also essential for progression and invasion of pancreatic ductal adenocarcinoma (PDAC) $(69,70)$. Increased expression of TRPM7 is correlated with poor patient prognosis $(69,71)$ and silencing of TRPM7 in PDAC cells reduces cancer cell invasion (70). Activation of TRPM7 induces secretion of MMP-2 from the Hsp90a/uPA/MMP-2 proteolytic axis, which degrades extracellular matrix (ECM) and facilitates cancer cell invasion (70).

In ovarian cancer (72) and bladder cancer, TRPM7 regulates cancer cell migration (60). TRPM7 also regulates proliferation of cancer cells (73-75), although silencing of TRPM7 does not affect the viability of breast cancer cells (61).

TRPM4 also regulates mechanotransduction in cell migration via promotion of focal adhesion disassembly, activation of FAK activation and Rac1, and actin cytoskeleton reorganization (76). Recently, it has been shown that TRPM2 regulates migration and invasion of gastric cancer cells in vitro, and also tumorigenesis and expression of $\mathrm{N}$-cadherin, snail, slug, integrins, and MMPs that are representative epithelial-mesenchymal transition (EMT) markers in vivo (77).

Several members of TRPV subfamily that are known to regulate mechanostransduction and migration have also been associated with metastasis. Recent studies highlighted a novel role of TRPV4 in breast cancer metastasis (78). Studies based on phosphoproteomics revealed a significant upregulation of TRPV4 in breast cancer metastasis in model cell lines, via extravasation. TRPV4 expression in human clinical samples using public databases revealed an increase in TRPV4 expression in basal subtype of breast cancer and was associated with a more aggressive phenotype and poor survival. Both silencing of TRPV4 and pharmacological inhibition of TRPV4 lead to suppression of migration and invasion of the TRPV4-expressing 4T07 breast cancer cell line, further confirming the role of TRPV4 in metastasis (78). Further functional studies revealed the role of TRPV4 in regulating cancer cell stiffness and cell cortex dynamics during cancer cell metastasis (78). Subsequent studies by the same research group attempted to establish the precise mechanism underlying the pro-migratory and pro-metastatic effects of TRPV4 in breast cancer (79). The findings suggested that TRPV4 mediates breast cancer metastasis by regulating the softness of cancer cells via $\mathrm{Ca}^{2+}$-dependent AKT/E-cadherin signaling as well as the expression of extracellular proteins involved in cytoskeleton and ECM remodeling (79). In addition to reports indicating TRPV4 function in breast cancer metastasis $(78,79)$, TRPV4 expression has been recently shown in gastric cancer metastasis (80). Activation of calcium-sensing receptor (CaSR), a Class C G-protein coupled receptor, induces growth and metastasis of human gastric cancer, mediated via TRPV4evoked increases in $\mathrm{Ca}^{2+}$ influx, which in turn, activates AKT/ $\beta$-catenin signaling pathway (80). The mechanosensitive ion channel TRPV4 has also been implicated in the migration of human hepatoblastoma HepG2 cells (81), which is one of the multiple steps involved in cancer metastasis (82). Application of a TRPV 4 agonist, $4 \alpha-$ PDD resulted in an increase in lamellipodial dynamics of HepG2 cells pre-treated with hepatocyte growth factor, indicating that functionally expressed TRPV4 channel mediates $\mathrm{Ca}^{2+}$ influx required for the migration of HepG2 cells (81). Although studies investigating the potential role of TRPV4 in cancer metastasis are still in their infancy, current findings should prompt further research into the likelihood of TRPV4 as a drug candidate in cancer therapy, especially in the case of metastatic cancers.

In conclusion, several TRP channels participate in mechanotransduction during cell migration, and also play a role in the metastasis of multiple cancer types.

\section{TRP CHANNELS IN PROSTATE CANCER}

Prostate cancer (PCa) is the second most common cause of cancer deaths among males in industrialized Western countries. With increased access to reliable biomarker detection, effective treatments for advanced PCa are still limited. Indeed, no effective treatments are available for $\mathrm{PCa}$, once it progresses to metastatic castration-resistant prostate cancer (mCRPC), which is refractory to current androgen deprivation therapy (ADT), and accounts for more than 250,000 cancer deaths worldwide, annually $(83,84)$. Several studies provide evidence supporting the role of TRP channels in PCa (85-87), especially, the members belonging to TRPV and TRPM subfamilies. TRP channels may be very promising players, because their expression and activity appear to regulate the progression of PCa $(21,88-91)$.

Silencing of TRPM4 reduces cell migration, but does not affect the growth of PC3 and DU145 cells, which are androgennonresponsive prostate cancer cell lines (92). miR-150 directly targets the TRPM4 gene and suppresses TRPM4 expression in PCa tissues (93). Upregulation of miR-150 or silencing of TRPM4 suppresses EMT phenotypes, migration and invasion, leading to inhibition of metastasis (93). In an independent study with PC3 cells, silencing of TRPM4 decreased the expression of Snail1, an EMT transcription factor, and also multiple representative EMT markers, thus inhibiting cell migration and invasion and validating the TRPM4-mediated regulation of migration and invasion (94). The TRPM2 channel has been shown to regulate the proliferation of PCa cell. Increased expression of TRPM2 is observed in $75 \%$ of PCa cells compared with matched benign cells $(16,95)$ and silencing of TRPM2 inhibited cancer cell growth $(16,87)$. TRPM4 is another TRPM channel identified as a player in PCa progression. TRPM4 was suggested as a cancer driver gene in CRPC (96). TRPM4 downregulates store-operated $\mathrm{Ca}^{2+}$ entry (SOCE) in normal, human prostate epithelial cells and DU145 cells, decreasing the driving force for $\mathrm{Ca}^{2+}$ (92). Silencing of TRPM4 reduces the migration, without affecting the proliferation, of 
PCa cells. TRPM7 also regulates the migration and invasion of PCa cells (97). TRPM7 is upregulated in PCa cells compared with prostate hyperplasia cells, and increases cancer cell migration. Silencing of TRPM7 in PCa cells reduced both migration and invasion of PCa cells from reversing their EMT status, downregulating MMPs and upregulating E-cadherin (97). Expression of TRPV1 is upregulated in high-grade PCa, when compared with tissues from healthy donors (98). Capsaicin, a TRPV1 agonist, inhibits proliferation of PC3 cells in a TRPV1-independent manner (99), via inhibition of coenzyme $\mathrm{Q}$ activity. Therefore, ROS generation is increased, and mitochondrial membrane potential is dissipated and caspase-3 is activated. By contrast, capsaicin was also found to stimulate TRPV1-dependent cell proliferation in androgen-responsive LNCaP cells, by decreasing ceramide levels and activating Akt and ERK pathways (100). The expression of TRPV2 in PCa was reported to be 12-fold higher in metastatic PCa than in non-metastatic PCa patients. TRPV2 overexpression in androgenresponsive $\mathrm{LNCaP}$ cells increases cell migration, while downregulation of TRPV2 reduces both growth and invasiveness of xenograft tumors with PC3 cells. Constitutive activation of TRPV2 and increased level of $\left[\mathrm{Ca}^{2+}\right]_{i}$, have been associated with TRPV2 function during the progression of androgen3responsive PCa to aggressive CRPC (101). In addition to their known regulation of migration, invasion and growth in PCa cells, it is still unknown whether any of TRP channels are involved in castration resistance, associated with aberrant activation of androgen signaling and resulting non-responsiveness to ADT.

\section{DISCUSSION}

The emergence of TRP channels as novel regulators in cancer growth and progression is specifically associated with their role in mechanotransduction and migration of cancer cells. However, the functional role of TRP channels appears to be unclear, suggesting the need for comprehensive studies. The involvement of TRP channels in mechanotransduction raises a few outstanding questions suggesting that TRP channels may regulate specific mechanosensitive processes and structures other than focal adhesions and actin dynamics during migration, and that YAP/TAZ signaling, a representative regulator of mechanosensitive transcriptional programs, may be linked to TRP signaling events.

Further elucidation of the role of TRP channels and changes in TRP channel expression in cancer progression are required for delineation of novel targets for new therapeutic alternatives in the 'war on cancer'.

\section{ACKNOWLEDGEMENTS}

This work was supported by the Basic Science Research Program, through the National Research Foundation of Korea (NRF), funded by the Ministry of Science, ICT \& Future Plann- ing (NRF-2017R1D1A1B03029063) and by the Korean Government (NRF-2018R1D1A1B07041381).

\section{CONFLICTS OF INTEREST}

The authors have no conflicting interests.

\section{REFERENCES}

1. Costa-Pereira AP and Cotter TG (1999) Molecular and cellular biology of prostate cancer-the role of apoptosis as a target for therapy. Prostate Cancer Prostatic Dis 2, 126-139

2. Tapia-Vieyra JV and Mas-Oliva J (2001) Apoptosis and cell death channels in prostate cancer. Arch Med Res 32, 175-185

3. Wertz IE and Dixit VM (2000) Characterization of calcium release-activated apoptosis of $\mathrm{LNCaP}$ prostate cancer cells. J Biol Chem 275, 11470-11477

4. Xue W, Zender L, Miething C et al (2007) Senescence and tumour clearance is triggered by p53 restoration in murine liver carcinomas. Nature 445, 656-660

5. Fels B, Bulk E, Petho Z and Schwab A (2018) The Role of TRP Channels in the Metastatic Cascade. Pharmaceuticals (Basel) 11, 48

6. Berridge MJ, Lipp P and Bootman MD (2000) The versatility and universality of calcium signalling. Nat Rev Mol Cell Biol 1, 11-21

7. Clapham DE (1995) Calcium signaling. Cell 80, 259-268

8. Csordas G, Varnai P, Golenar T et al (2010) Imaging interorganelle contacts and local calcium dynamics at the ER-mitochondrial interface. Mol Cell 39, 121-132

9. Baudouin-Legros $M$, Brouillard $F$, Tondelier D, Hinzpeter A and Edelman A (2003) Effect of ouabain on CFTR gene expression in human Calu-3 cells. Am J Physiol Cell Physiol 284, C620-626

10. McConkey DJ and Orrenius S (1997) The role of calcium in the regulation of apoptosis. Biochem Biophys Res Commun 239, 357-366

11. Parekh AB (2011) Decoding cytosolic Ca2 + oscillations. Trends Biochem Sci 36, 78-87

12. Berridge MJ (1997) The AM and FM of calcium signalling. Nature 386, 759-760

13. Smedler E and Uhlen P (2014) Frequency decoding of calcium oscillations. Biochim Biophys Acta 1840, 964-969

14. Cullen PJ (2003) Calcium signalling: the ups and downs of protein kinase C. Curr Biol 13, R699-701

15. Hu Q, Deshpande S, Irani K and Ziegelstein RC (1999) $[\mathrm{Ca}(2+)](\mathrm{i})$ oscillation frequency regulates agonist-stimulated NF-kappaB transcriptional activity. J Biol Chem 274, 33995-33998

16. Zeng X, Sikka SC, Huang L et al (2010) Novel role for the transient receptor potential channel TRPM2 in prostate cancer cell proliferation. Prostate Cancer Prostatic Dis 13, 195-201

17. Bidaux G, Beck B, Zholos A et al (2012) Regulation of activity of transient receptor potential melastatin 8 
(TRPM8) channel by its short isoforms. J Biol Chem 287, 2948-2962

18. Bidaux G, Borowiec AS, Gordienko D et al (2015) Epidermal TRPM8 channel isoform controls the balance between keratinocyte proliferation and differentiation in a cold-dependent manner. Proc Natl Acad Sci U S A 112, E3345-3354

19. Patapoutian A, Tate S and Woolf CJ (2009) Transient receptor potential channels: targeting pain at the source. Nat Rev Drug Discov 8, 55-68

20. Prevarskaya N, Zhang L and Barritt G (2007) TRP channels in cancer. Biochim Biophys Acta 1772, 937946

21. Gkika D and Prevarskaya N (2009) Molecular mechanisms of TRP regulation in tumor growth and metastasis. Biochim Biophys Acta 1793, 953-958

22. Santoni G, Farfariello V and Amantini C (2011) TRPV channels in tumor growth and progression. Adv Exp Med Biol 704, 947-967

23. Talmadge JE and Fidler IJ (2010) AACR centennial series: the biology of cancer metastasis: historical perspective. Cancer Res 70, 5649-5669

24. Hanahan D and Weinberg RA (2011) Hallmarks of cancer: the next generation. Cell 144, 646-674

25. Cosens DJ and Manning A (1969) Abnormal electroretinogram from a Drosophila mutant. Nature 224, 285-287

26. Yoshida T, Inoue R, Morii T et al (2006) Nitric oxide activates TRP channels by cysteine S-nitrosylation. Nat Chem Biol 2, 596-607

27. Rizza S and Filomeni G (2018) Role, targets and regulation of (de)nitrosylation in Malignancy. Front Oncol 8, 334

28. Goel M, Sinkins WG and Schilling WP (2002) Selective association of TRPC channel subunits in rat brain synaptosomes. J Biol Chem 277, 48303-48310

29. Hofmann T, Schaefer M, Schultz G and Gudermann T (2002) Subunit composition of mammalian transient receptor potential channels in living cells. Proc Natl Acad Sci U S A 99, 7461-7466

30. Schaefer M (2005) Homo- and heteromeric assembly of TRP channel subunits. Pflugers Arch 451, 35-42

31. Strubing C, Krapivinsky G, Krapivinsky L and Clapham DE (2003) Formation of novel TRPC channels by complex subunit interactions in embryonic brain. J Biol Chem 278, 39014-39019

32. Strubing C, Krapivinsky G, Krapivinsky L and Clapham DE (2001) TRPC1 and TRPC5 form a novel cation channel in mammalian brain. Neuron 29,645-655

33. Liu X, Bandyopadhyay BC, Singh BB, Groschner K and Ambudkar IS (2005) Molecular analysis of a storeoperated and 2-acetyl-sn-glycerol-sensitive non-selective cation channel. Heteromeric assembly of TRPC1-TRPC3. J Biol Chem 280, 21600-21606

34. Gudermann T, Hofmann T, Mederos y Schnitzler $M$ and Dietrich A (2004) Activation, subunit composition and physiological relevance of DAG-sensitive TRPC proteins. Novartis Found Symp 258, 103-118; discussion 118$122,155-159,263-266$

35. Zagranichnaya TK, Wu X and Villereal ML (2005)
Endogenous TRPC1, TRPC3, and TRPC7 proteins combine to form native store-operated channels in HEK-293 cells. J Biol Chem 280, 29559-29569

36. Poteser M, Graziani A, Rosker C et al (2006) TRPC3 and TRPC4 associate to form a redox-sensitive cation channel. Evidence for expression of native TRPC3-TRPC4 heteromeric channels in endothelial cells. J Biol Chem 281, 13588-13595

37. Plant TD and Schaefer M (2003) TRPC4 and TRPC5: receptor-operated $\mathrm{Ca} 2+$-permeable nonselective cation channels. Cell Calcium 33, 441-450

38. Plant TD and Schaefer M (2005) Receptor-operated cation channels formed by TRPC4 and TRPC5. Naunyn Schmiedebergs Arch Pharmacol 371, 266-276

39. Venkatachalam K, Hofmann T and Montell C (2006) Lysosomal localization of TRPML3 depends on TRPML2 and the mucolipidosis-associated protein TRPML1. J Biol Chem 281, 17517-17527

40. Curcio-Morelli C, Zhang P, Venugopal B et al (2010) Functional multimerization of mucolipin channel proteins. J Cell Physiol 222, 328-335

41. Tsuruda PR, Julius D and Minor DL Jr (2006) Coiled coils direct assembly of a cold-activated TRP channel. Neuron 51, 201-212

42. Chubanov V, Mederos y Schnitzler M, Waring J, Plank A and Gudermann T (2005) Emerging roles of TRPM6/ TRPM7 channel kinase signal transduction complexes. Naunyn Schmiedebergs Arch Pharmacol 371, 334-341

43. Chubanov V, Waldegger S, Mederos y Schnitzler M et al (2004) Disruption of TRPM6/TRPM7 complex formation by a mutation in the TRPM6 gene causes hypomagnesemia with secondary hypocalcemia. Proc Natl Acad Sci U S A 101, 2894-2899

44. Jiang LH (2007) Subunit interaction in channel assembly and functional regulation of transient receptor potential melastatin (TRPM) channels. Biochem Soc Trans 35, 86-88

45. Li M, Jiang J and Yue L (2006) Functional characterization of homo- and heteromeric channel kinases TRPM6 and TRPM7. J Gen Physiol 127, 525-537

46. Cheng W, Yang F, Takanishi CL and Zheng J (2007) Thermosensitive TRPV channel subunits coassemble into heteromeric channels with intermediate conductance and gating properties. J Gen Physiol 129, 191-207

47. Hellwig N, Albrecht N, Harteneck C, Schultz G and Schaefer M (2005) Homo- and heteromeric assembly of TRPV channel subunits. J Cell Sci 118, 917-928

48. Liapi A and Wood JN (2005) Extensive co-localization and heteromultimer formation of the vanilloid receptorlike protein TRPV2 and the capsaicin receptor TRPV1 in the adult rat cerebral cortex. Eur J Neurosci 22, 825-834

49. Smith GD, Gunthorpe MJ, Kelsell RE et al (2002) TRPV3 is a temperature-sensitive vanilloid receptor-like protein. Nature 418, 186-190

50. Garcia-Sanz N, Fernandez-Carvajal A, Morenilla-Palao C et al (2004) Identification of a tetramerization domain in the $\mathrm{C}$ terminus of the vanilloid receptor. J Neurosci 24, 5307-5314

51. Vlachova V, Teisinger J, Susankova K, Lyfenko A, Ettrich $R$ and Vyklicky L (2003) Functional role of C-terminal 
cytoplasmic tail of rat vanilloid receptor 1. J Neurosci 23, 1340-1350

52. Zhang F, Liu S, Yang F, Zheng J and Wang K (2011) Identification of a tetrameric assembly domain in the $C$ terminus of heat-activated TRPV1 channels. J Biol Chem 286, 15308-15316

53. Kopanska KS, Alcheikh Y, Staneva R, Vignjevic D and Betz T (2016) Tensile forces originating from cancer spheroids facilitate tumor invasion. PLoS One 11, $\mathrm{e} 0156442$

54. Wei SC and Yang J (2016) Forcing through Tumor Metastasis: The Interplay between tissue rigidity and epithelial-mesenchymal transition. Trends Cell Biol 26, 111-120

55. Broders-Bondon F, Nguyen Ho-Bouldoires TH, FernandezSanchez ME and Farge E (2018) Mechanotransduction in tumor progression: The dark side of the force. J Cell Biol $217,1571-1587$

56. Chubanov V, Mittermeier L and Gudermann T (2018) Role of kinase-coupled TRP channels in mineral homeostasis. Pharmacol Ther 184, 159-176

57. Schilling T, Miralles F and Eder C (2014) TRPM7 regulates proliferation and polarisation of macrophages. J Cell Sci 127, 4561-4566

58. Clark K, Langeslag M, van Leeuwen B et al (2006) TRPM7, a novel regulator of actomyosin contractility and cell adhesion. EMBO J 25, 290-301

59. Nishitani WS, Alencar AM and Wang Y (2015) Rapid and localized mechanical stimulation and adhesion assay: TRPM7 involvement in calcium signaling and cell adhesion. PLoS One 10, e0126440

60. Gao SL, Kong CZ, Zhang Z, Li ZL, Bi JB and Liu XK (2017) TRPM7 is overexpressed in bladder cancer and promotes proliferation, migration, invasion and tumor growth. Oncol Rep 38, 1967-1976

61. Middelbeek J, Kuipers AJ, Henneman L et al (2012) TRPM7 is required for breast tumor cell metastasis. Cancer Res 72, 4250-4261

62. Wei C, Wang X, Chen M, Ouyang K, Song LS and Cheng $H$ (2009) Calcium flickers steer cell migration. Nature 457, 901-905

63. Su LT, Agapito MA, Li M et al (2006) TRPM7 regulates cell adhesion by controlling the calcium-dependent protease calpain. J Biol Chem 281, 11260-11270

64. Guilbert A, Gautier M, Dhennin-Duthille I et al (2013) Transient receptor potential melastatin 7 is involved in oestrogen receptor-negative metastatic breast cancer cells migration through its kinase domain. Eur J Cancer 49, 3694-3707

65. Meng X, Cai C, Wu J et al (2013) TRPM7 mediates breast cancer cell migration and invasion through the MAPK pathway. Cancer Lett 333, 96-102

66. Clark K, Middelbeek J, Lasonder E et al (2008) TRPM7 regulates myosin IIA filament stability and protein localization by heavy chain phosphorylation. J Mol Biol 378, 790-803

67. Chen JP, Wang J, Luan Y et al (2015) TRPM7 promotes the metastatic process in human nasopharyngeal carcinoma. Cancer Lett 356, 483-490

68. Chen JP, Luan Y, You CX, Chen XH, Luo RC and Li R
(2010) TRPM7 regulates the migration of human nasopharyngeal carcinoma cell by mediating $\mathrm{Ca}(2+)$ influx. Cell Calcium 47, 425-432

69. Yee NS, Kazi AA, Li Q, Yang Z, Berg A and Yee RK (2015) Aberrant over-expression of TRPM7 ion channels in pancreatic cancer: required for cancer cell invasion and implicated in tumor growth and metastasis. Biol Open 4, 507-514

70. Rybarczyk P, Vanlaeys A, Brassart B et al (2017) The transient receptor potential melastatin 7 channel regulates pancreatic cancer cell invasion through the Hsp90alpha/uPAMMP2 pathway. Neoplasia 19 288-300

71. Yee NS, Chan AS, Yee JD and Yee RK (2012) TRPM7 and TRPM8 ion channels in pancreatic adenocarcinoma: potential roles as cancer biomarkers and targets. Scientifica (Cairo) 2012, 415158

72. Wang J, Liao QJ, Zhang Y et al (2014) TRPM7 is required for ovarian cancer cell growth, migration and invasion. Biochem Biophys Res Commun 454, 547-553

73. Dhennin-Duthille I, Gautier M, Faouzi M et al (2011) High expression of transient receptor potential channels in human breast cancer epithelial cells and tissues: correlation with pathological parameters. Cell Physiol Biochem 28, 813-822

74. Jiang J, Li MH, Inoue K, Chu XP, Seeds J and Xiong ZG (2007) Transient receptor potential melastatin 7-like current in human head and neck carcinoma cells: role in cell proliferation. Cancer Res 67, 10929-10938

75. Yee NS, Zhou W and Liang IC (2011) Transient receptor potential ion channel Trpm7 regulates exocrine pancreatic epithelial proliferation by Mg2 +-sensitive Socs3a signaling in development and cancer. Dis Model Mech 4, 240-254

76. Caceres M, Ortiz L, Recabarren T et al (2015) TRPM4 Is a novel component of the adhesome required for focal adhesion disassembly, migration and contractility. PLoS One 10, e0130540

77. Almasi S, Sterea AM, Fernando W et al (2019) TRPM2 ion channel promotes gastric cancer migration, invasion and tumor growth through the AKT signaling pathway. Sci Rep 9, 4182

78. Lee WH, Choong LY, Mon NN et al (2016) TRPV4 regulates breast cancer cell extravasation, stiffness and actin cortex. Sci Rep 6, 27903

79. Lee WH, Choong LY, Jin TH et al (2017) TRPV4 plays a role in breast cancer cell migration via $\mathrm{Ca}(2+)$ dependent activation of AKT and downregulation of E-cadherin cell cortex protein. Oncogenesis 6, e338

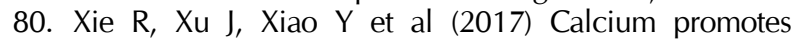
human gastric cancer via a novel coupling of calcium-sensing receptor and TRPV4 channel. Cancer Res 77, 6499-6512

81. Waning J, Vriens J, Owsianik G et al (2007) A novel function of capsaicin-sensitive TRPV1 channels: involvement in cell migration. Cell Calcium 42, 17-25

82. Sahai E (2007) Illuminating the metastatic process. Nat Rev Cancer 7, 737-749

83. Jemal A, Bray F, Center MM, Ferlay J, Ward E and Forman D (2011) Global cancer statistics. CA Cancer J 
Clin 61, 69-90

84. Siegel RL, Miller KD and Jemal A (2018) Cancer statistics, 2018. CA Cancer J Clin 68, 7-30

85. Gkika D and Prevarskaya N (2011) TRP channels in prostate cancer: the good, the bad and the ugly? Asian J Androl 13, 673-676

86. Prevarskaya N, Flourakis $M$, Bidaux G, Thebault $S$ and Skryma R (2007) Differential role of TRP channels in prostate cancer. Biochem Soc Trans 35, 133-135

87. Van Haute C, De Ridder D and Nilius B (2010) TRP channels in human prostate. Scientific World Journal 10, 1597-1611

88. Flourakis $M$ and Prevarskaya N (2009) Insights into $\mathrm{Ca} 2+$ homeostasis of advanced prostate cancer cells. Biochim Biophys Acta 1793, 1105-1109

89. Prevarskaya N, Skryma R and Shuba Y (2011) Calcium in tumour metastasis: new roles for known actors. Nat Rev Cancer 11, 609-618

90. Skryma R, Prevarskaya N, Gkika D and Shuba Y (2011) From urgency to frequency: facts and controversies of TRPs in the lower urinary tract. Nat Rev Urol 8, 617-630

91. Gkika D, Lemonnier L, Shapovalov G et al (2015) TRP channel-associated factors are a novel protein family that regulates TRPM8 trafficking and activity. J Cell Biol 208, 89-107

92. Holzmann C, Kappel S, Kilch T et al (2015) Transient receptor potential melastatin 4 channel contributes to migration of androgen-insensitive prostate cancer cells. Oncotarget 6, 41783-41793

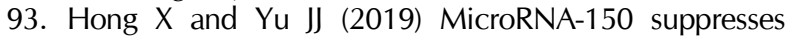
epithelial-mesenchymal transition, invasion, and metastasis in prostate cancer through the TRPM4-mediated betacatenin signaling pathway. Am J Physiol Cell Physiol
316, C463-C480

94. Sagredo Al, Sagredo EA, Pola $\mathrm{V}$ et al (2019) TRPM4 channel is involved in regulating epithelial to mesenchymal transition, migration, and invasion of prostate cancer cell lines. J Cell Physiol 234, 2037-2050

95. Hantute-Ghesquier A, Haustrate A, Prevarskaya N and Lehen'kyi V (2018) TRPM family channels in cancer. Pharmaceuticals (Basel) 11, 58

96. Schinke EN, Bii V, Nalla A et al (2014) A novel approach to identify driver genes involved in androgenindependent prostate cancer. Mol Cancer 13, 120

97. Chen L, Cao R, Wang G et al (2017) Downregulation of TRPM7 suppressed migration and invasion by regulating epithelial-mesenchymal transition in prostate cancer cells. Med Oncol 34, 127

98. Czifra G, Varga A, Nyeste K et al (2009) Increased expressions of cannabinoid receptor- 1 and transient receptor potential vanilloid-1 in human prostate carcinoma. J Cancer Res Clin Oncol 135, 507-514

99. Sanchez AM, Sanchez MG, Malagarie-Cazenave S, Olea $\mathrm{N}$ and Diaz-Laviada I (2006) Induction of apoptosis in prostate tumor PC-3 cells and inhibition of xenograft prostate tumor growth by the vanilloid capsaicin. Apoptosis 11, 89-99

100. Malagarie-Cazenave S, Olea-Herrero N, Vara D and Diaz-Laviada I (2009) Capsaicin, a component of red peppers, induces expression of androgen receptor via $\mathrm{PI} 3 \mathrm{~K}$ and MAPK pathways in prostate LNCaP cells. FEBS Lett 583, 141-147

101. Monet M, Lehen'kyi V, Gackiere F et al (2010) Role of cationic channel TRPV2 in promoting prostate cancer migration and progression to androgen resistance. Cancer Res 70, 1225-1235 